\title{
Childhood temperament and long-term sickness absence in adult life
}

Max Henderson, Matthew Hotopf and David A. Leon

\section{Background}

Little is known as to whether childhood temperament is associated with long-term sickness absence in adult life.

\section{Aims}

To explore the associations between childhood temperament and long-term sickness absence in middle age.

\section{Method}

The Aberdeen Children of the 1950s study is comprised of 12150 children born in Aberdeen 1950-55. Teachers completed the Aberdeen-London Child Behaviour Scale (Rutter B) for all participants in 1964. Current employment status was ascertained for 7183 (63.7\%) in 2001.

\section{Results}

Five and a half per cent of responders classified themselves as 'permanently sick or disabled' at follow-up. 'Often complains of aches and pains' (OR=6.75, 95\% Cl 1.28-35.5) and 'Often appears miserable or unhappy' (OR=3.81, 95\% C 1.01-14.4) were strongly associated with being permanently sick or disabled following adjustment for year of birth, gender, IQ and father's social class.

\section{Conclusions}

Childhood temperament is strongly associated with sickness absence in middle age.

\section{Declaration of interest}

None. Funding detailed in Acknowledgements.
Sickness absence is a major public health problem. ${ }^{1}$ The most common reasons are psychiatric conditions ${ }^{2}$ and musculoskeletal disorders that are often 'medically unexplained'. ${ }^{3}$ Self-report measures of the physical and psychosocial work environment have shown associations with sickness absence. ${ }^{4,5} \mathrm{Most}^{6,7}$ but not all ${ }^{8,9}$ studies using objective measures of the psychosocial work environment have failed to show this association. Individual perceptions of the work environment might account for the discrepant findings between subjective and objective measures. ${ }^{10}$ Hence, the true association might be between the way an individual perceives the work environment, as opposed to the environment itself, and adverse occupational outcomes. Individual perceptions are influenced by temperament and early life. Childhood experiences of ill health and the development of avoidance as a coping strategy are shared risk factors for both common mental disorders and medically unexplained symptoms such as low back pain. ${ }^{11-13}$ We therefore sought to examine the association of long-term sickness absence in middle age with absence from school and childhood temperament factors known to be associated with common mental disorders and functional somatic symptoms in later life.

\section{Method}

\section{Participants}

The Aberdeen Child Development Study (ACDS) was a crosssectional survey of all children in primary school in Aberdeen between 1962 and 1964. In 1999 the subset of 12150 ACDS children born in Aberdeen were reconstituted as the Aberdeen Children of the 1950s study. ${ }^{14,15}$ In total 12013 (99\%) of the original participants were traced and 11282 were mailed a questionnaire in 2001. The methodology and outcome of the questionnaire survey have been described in detail elsewhere. ${ }^{16}$ Of the original cohort, 479 had died, 291 were known to have emigrated and 62 were not contacted as they were either in prison or in long-term psychiatric care. Of the 11282 who were eligible to receive a questionnaire, $7183(63.7 \%)$ completed one and returned it to the investigators.

\section{Childhood measures}

At the time of the original Aberdeen Child Development Study, detailed childhood data were collected on cognitive performance from results of routine school IQ tests conducted at age 7,9 and 11 years. At age 11 years, IQ was derived from the standardised results of the national reading tests I and II and the national arithmetic tests I and II. In addition, socio-demographic and anthropometric data were also collected. School attendance was described in the ACDS as the proportion of half-days absent from school in 1962-1964 aggregated in three bands. The AberdeenLondon Child Behaviour Scale ${ }^{17}$ was completed by school teachers (Rutter B). It has been used in other studies looking at early life risk factors for occupational outcomes ${ }^{18}$ and has been validated using structured interviews with both parents and children. ${ }^{19}$ Teachers responded on a 3-point Likert scale: 'doesn't apply', 'applies somewhat' or 'certainly applies'. We measured anxious or depressive symptoms using responses to two statements: 'often appears miserable, unhappy, tearful or distressed' and 'tends to be fearful or afraid of things or new situations'. The teacher's perception of unjustified school absences was measured on the statement: 'tends to be absent from school for trivial reasons' and tendency to experience physical symptoms on the statement: 'often complains of aches or pains'. Social class of father in childhood was also collected based on children's report of their father's occupation.

\section{Follow-up}

The follow-up questionnaire in middle age asked about the participant's health, occupation, education and living conditions. We defined the outcome for this study as whether or not the respondents classified themselves as 'permanently sick or disabled' in response to a question on current employment situation.

\section{Analyses}

We tested associations between variables of interest using $\chi^{2}$ tests (and where appropriate tests for trend). Odds ratios (OR) of being permanently sick or disabled were estimated using logistic 
regression. All models included gender and year of birth. Other covariables were included in further models. IQ aged 11 and father's social class were considered possible confounders and highest educational attainment was considered a potential mediating factors. The effects of each were examined in turn. Analyses were performed using Stata version 9.2 for Windows.

\section{Ethical approval}

The Aberdeen Children of the 1950s study was approved by the Scottish Multi-Centre Research Ethics Committee, the Scottish Privacy Advisory Committee and various local ethics committees.

\section{Results}

Of the 7183 participants who returned a questionnaire in 2001, 7161 gave information about their current employment status. Of these, $392(5.5 \%, 95 \%$ CI 5-6) identified themselves as 'permanently sick or disabled'. The distribution of the exposures of interest is shown in Table 1 together with the numbers missing from each variable.

Questionnaire response was strongly related to each of the items of the Rutter B scale, with response being much lower among those who were identified by the teacher as having a problem.

\section{Univariable analyses}

There was no evidence that being permanently sick or disabled was associated with the proportion of school days missed (online Table DS1). There was weak evidence that those reported to be fearful or afraid were more likely to be permanently sick or disabled but good evidence that the other elements of the Rutter B score were associated with this outcome. Approximately a quarter of those reported to be definitely miserable and unhappy or who were felt often to complain of aches and pains, and over $10 \%$ of those who were definitely fearful or absent for trivial reasons described themselves as permanently sick or disabled 40 years later. These associations showed a strong trend such that the more certain the teacher was that the statement applied, the more likely the participant was to be found to be permanently sick or disabled in middle age.

The associations between the potential confounders and mediators and being permanently sick or disabled are also shown in online Table DS1. Although there was no evidence of an association with gender, there was strong evidence that earlier year of birth, lower IQ aged 11, lower paternal social class and lower education attainment were all associated with being permanently sick or disabled.

\section{Multivariable analyses}

The effects of the potential confounding and mediating factors were examined. The amount of time off school and the teachers' statements from the Rutter B questionnaire were adjusted for gender and age at questionnaire completion and then for other variables in sequence. A further analysis included all possible confounders. Education was then added as a potential mediator (online Table DS2), followed by measures of socio-economic status in 2001.

Level of school absence did not show any association with 'permanently sick or disabled' in 2001 either in the basic model adjusted for gender and year of birth or with further adjustment. Being perceived as anxious was only weakly associated with 'permanently sick or disabled', and this only for the 'certainly applies' category. This association became non-significant on adjustment for confounders beyond gender and year of birth. The remaining items from the Rutter scale showed a clear dose-response relationship with being permanently sick or

\begin{tabular}{|c|c|c|c|}
\hline Variable & $\begin{array}{l}\text { Total cohort defined in } 1962 \text {, } \\
\qquad(\%)(n=12150)\end{array}$ & $\begin{array}{c}2001 \text { responders, } \\
n(\%)^{\mathrm{a}}\end{array}$ & $P$ \\
\hline \multicolumn{4}{|l|}{ School absence } \\
\hline $0-12.5 \%$ & $11624(97.1)$ & $6943(59.7)$ & \multirow[t]{4}{*}{$<0.001$} \\
\hline $12.5-25 \%$ & $286(2.4)$ & $143(50)$ & \\
\hline$>25 \%$ & $56(0.5)$ & $24(42.9)$ & \\
\hline Total & 11966 & $7110(59.4)$ & \\
\hline \multicolumn{4}{|c|}{ Rutter $B$} \\
\hline \multicolumn{4}{|c|}{ Often complains of pains or aches } \\
\hline No & $11355(96.5)$ & $6812(60)$ & \multirow[t]{4}{*}{0.002} \\
\hline Somewhat & $344(2.9)$ & 179 (52) & \\
\hline Certainly & $72(0.6)$ & $37(51.4)$ & \\
\hline Total & 11771 & $7028(59.7)$ & \\
\hline \multicolumn{4}{|c|}{ Often appears miserable or unhappy } \\
\hline No & $10805(91.8)$ & $6529(60.4)$ & \multirow[t]{4}{*}{$<0.001$} \\
\hline Somewhat & $876(7.4)$ & $455(51.9)$ & \\
\hline Certainly & $91 \quad(0.8)$ & $44(48.4)$ & \\
\hline Total & 11772 & $7028(59.7)$ & \\
\hline \multicolumn{4}{|c|}{ Tends to be absent for trivial reasons } \\
\hline No & $11114(94.4)$ & $6725(60.5)$ & \multirow[t]{4}{*}{$<0.001$} \\
\hline Somewhat & $497 \quad(4.2)$ & $236(47.5)$ & \\
\hline Certainly & 158 (1.3) & $66(41.8)$ & \\
\hline Total & 11769 & 7027 (59.7) & \\
\hline \multicolumn{4}{|c|}{ Tends to be fearful or afraid } \\
\hline No & 9971 (84.8) & $5994(60.1)$ & \multirow[t]{4}{*}{0.005} \\
\hline Somewhat & $1605(13.6)$ & $925(57.6)$ & \\
\hline Certainly & $189(1.6)$ & $103(54.5)$ & \\
\hline Total & 11765 & $7022(59.7)$ & \\
\hline
\end{tabular}


disabled even following adjustment for potential confounders, the exception being 'appears miserable' where in the final model only the 'certainly applies' category was associated.

The role of educational attainment was examined as a possible mediating factor between risk factors in childhood and adult occupational outcomes. When entered into a model without IQ there was an association with 'permanently sick or disabled' but when IQ was subsequently added the impact of education disappeared (results not shown). The addition of educational attainment to a model already containing childhood IQ and father's social class attenuated the associations of the Rutter score items with risk of being permanently sick or disabled, although significant trends remained with 'complains of aches and pains' and tendency to have trivial absence from school. Although the addition of socio-economic status variables attenuated the effect of 'appears miserable', the data-set was much reduced in size and given that they were collected at the same time as the outcome variable it remains unclear if they mediate the association between childhood exposures and being permanently sick or disabled or are a consequence of being permanently sick or disabled (online Table DS2).

\section{Discussion}

\section{Key findings}

This study used data from the Aberdeen Children of the 1950s study to examine factors in children of primary school age which might predict employment status 39 years later. We have shown that some problematic aspects of behaviour and temperament identified by teachers are associated with no longer being in the labour force because of permanent sickness or disability. Children whose teachers described them as having frequent aches and pains, appearing to be miserable and often being off school for trivial reasons were more prone to be permanently off work sick or disabled.

\section{Strengths and limitations of the study}

The large sample size, long (39-year) follow-up and longitudinal design are the main strengths of this study. However, these exposure variables are 'one-off' reports and the extent to which short-term factors (such as how the child behaved on the day) might have affected the teacher's assessment is not known. None the less, the statements are carefully worded (e.g. 'tends to', 'often') to uncover the child's more enduring traits.

'Permanently sick or disabled' identifies a group endorsing quite a 'strong' statement about their employment status but it was not further defined and it is likely that this group contained a mixture of those ill-health retired and those on incapacity benefit. However, in some other countries 'permanent disability' has a formal definition, requires medical endorsement and is a gateway to a disability pension. This was not the case in our study

The major limitation of the study is that only $64 \%$ of those eligible responded to the follow-up questionnaire in 2001. Unusually, factors predicting non-response in this cohort have been described. Nishiwaki et $a l^{16}$ have shown that male gender, lower IQ, low paternal social class, having parents who were unmarried at the time of one's birth, being shorter and lighter, and having a higher total from all 26 items on the Rutter B scale were associated with non-response to the follow-up questionnaire. In this study we have shown that the particular items of the Rutter scale that we have focused on are also associated with nonresponse. As a result, those with the exposure of interest are underrepresented in the final population being studied. However, it is difficult to imagine that the effects of the exposure variables on employment status would have differed between responders and non-responders in such a way as to lead us to find a spurious association with being permanently sick or disabled.

Another limitation is that we do not know the 'reasons' for their sickness absence. These data would not necessarily weaken the associations described but might help illuminate causal pathways.

Alternative mechanisms for the relationships we have found between childhood variables and functional incapacity in adult life were considered. We were able to adjust for a number of plausible potential confounding factors in our analysis. Socio-economic status is associated with most health-related outcomes, including sickness absence. ${ }^{20}$ Paternal social class in childhood was shown here to be associated with the main outcome variable. Controlling for this variable led to only a small reduction in the odds ratios.

It is possible that the effect of problematic aspects of childhood behaviour and temperament on employment status in middle age is mediated through attained level of education. Adjustment for education over and above childhood confounders attenuated the strength of associations with being permanently sick or disabled, although the associations with two of the Rutter score variables remained statistically significant. We therefore conclude that education may play a mediating role between the responses to the Rutter questions and being permanently sick or disabled in 2001, although it is very likely that the association of childhood characteristics and being permanently sick or disabled also involves other pathways.

It is possible that other unknown or unmeasured confounders are responsible. For example, some of those who were miserable or complaining of aches and pains were already affected by physical health problems that made them more likely to leave the workforce. It would be surprising though if this provided a full explanation of the association, given that these children were well enough to be in school and those permanently sick or disabled in 2001 did not take more time off school.

Our findings might not be generalisable to the whole of the UK as there may be factors specific to this generation of people born in Scotland in the 1950s. To this end, further studies of this association in different birth cohorts and geographic areas are a priority to see if these associations can be confirmed.

We can only speculate about the mechanisms which might link the childhood variables with adult occupational outcomes. It is not clear how low IQ has an impact on being permanently sick or disabled aged 50. Occupational role or income may be responsible, as those with higher IQs tend to be employed in higher status, better paid jobs and suffer less from conditions which might lead to an early departure from the workforce. An individual's social functioning may have a role. Those with higher IQ may be able to understand how to make healthier lifestyle choices, to avoid factors which might lead to illness or disability. They may be more 'health literate' and thus better able to access suitable help or treatment if they do become ill. They might also be better able to negotiate with an employer should they become ill. This association between IQ and long-term occupational outcomes has only been described once before, in a cohort of Swedish army recruits. ${ }^{21}$

Why is complaining of aches and pains at primary school associated with occupational function in middle life? Demonstrable physical disease seems unlikely to be the explanation given that most childhood symptoms are not related to physical disease, ${ }^{13}$ and the effect is visible over the life course, so it seems likely that we have tapped into an aspect of individual temperament. Symptoms in childhood have long-term consequences in adult functioning with evidence that they are associated with increased symptoms of depression and anxiety 
as well as continued unexplained physical symptoms. ${ }^{12,13,22}$ Symptom perception may be different, with relatively minor insults being more likely to result in a symptom such as pain. The likelihood of reporting or complaining about a symptom might also be different with these individuals less able to manage discomfort themselves and instead seeking help or reassurance from others. These possibilities are not mutually exclusive and the question is too blunt to be able to dissect this further. If these insights are to be translated into opportunities for interventions, more research will be needed on the way in which these aspects of individual temperament lead to sickness absence.

\section{Implications and future research}

These findings suggest that there may be a range of vulnerabilities established in childhood that impact on long-term sickness absence. Thus, an exclusive focus upon the psychosocial work environment may miss additional important risk factors. Aspects of individual personality or temperament recognisable in early childhood appear to play a role. Further research is needed both to replicate these findings in other populations and to characterise in greater detail the relative importance of childhood factors. Beyond this, research needs to be done in the way in which these individual factors relate to the occupational factors (physical and psychosocial) that have already been shown to be associated with long-term sickness absence and ill-health retirement. Based on the findings in this study we suggest that a life-course approach is required to understand the mechanisms by which early temperament influences individual perceptions of the workplace and how these variables in turn influence long-term sickness absence.

Max Henderson, MRCPsych, Matthew Hotopf, MRCPsych, Department of Psychological Medicine, Institute of Psychiatry, Kings College London; David A. Leon PhD, London School of Hygiene \& Tropical Medicine, London, UK

Correspondence: Max Henderson, Institute of Psychiatry, Kings College London, Department of Psychological Medicine, Weston Education Centre Cutcombe Road, London SE5 9RJ, UK. Email: m.henderson@iop.kcl.ac.uk

First received 22 Aug 2007, final revision 28 Aug 2008, accepted 8 Sep 2008

\section{Acknowledgements}

We are grateful to Raymond IIIsley for providing the original data from the Aberdeen Child Development Survey. Heather Clark managed the study at the Dugald Baird Centre Aberdeen. The follow-up of the Aberdeen Children of the 1950s Study from 1998 was funded by the UK Medical Research Council and the Chief Scientists Office, Scottish Executive Health Department. M. Henderson is funded by an MRC research training fellowship in Health Services \& Health of the Public Research. This work is independent of the funder. M. Hotopf is funded by the South London and Maudsley NHS Foundation Trust, King's College London, NIHR Biomedical Research Centre.

\section{References}

1 Henderson $\mathrm{M}$, Glozier N, Holland Elliott K. Long term sickness absence. BMJ 2005; 330: 802-3.
2 National Statistics. Health and Safety Statistics 2006/7. Health and Safety Executive, 2007

3 Deyo RA, Weinstein JN. Low back pain. N Engl J Med 2001; 344: 363-70.

4 Bang Christensen $\mathrm{K}$, Lund $\mathrm{T}$, Labriola M, Villadsen $\mathrm{E}$, Bultmann $\mathrm{U}$. The fraction of long-term sickness absence attributable to work environmental factors: prospective results from the Danish Work Environment Cohort Study. Occup Environ Med 2007; 64: 487-9.

5 Lund T, Labriola M, Christensen KB, Bultmann U, Villadsen E. Physical work environment risk factors for long term sickness absence: prospective findings among a cohort of 5357 employees in Denmark. BMJ 2006; 332 449-52.

6 Stansfeld SA, North FM, White I, Marmot MG. Work characteristics and psychiatric disorder in civil servants in London. J Epidemiol Community Health 1995; 49: 48-53.

7 Boedeker W. Associations between workload and diseases rarely occurring in sickness absence data. J Occup Environ Med 2001; 43: 1081-8.

8 Dwyer DJ, Ganster D. The effects of job demands and control on employee attendance and satisfaction. J Organ Behav 1991; 12: 595-608.

9 Greiner BA, Krause N, Ragland DR, Fisher JM. Objective stress factors, accidents, and absenteeism in transit operators: a theoretical framework and empirical evidence. J Occup Health Psychol 1998; 3: 130-46.

10 Stansfeld S. Work, personality and mental health. Br J Psychiatry 2002; 181: 96-8.

11 Craig TK, Boardman AP, Mills K, Daly-Jones O, Drake H. The South London Somatisation Study. I: Longitudinal course and the influence of early life experiences. Br J Psychiatry 1993; 163: 579-88.

12 Fearon $\mathrm{P}$, Hotopf M. Relation between headache in childhood and physical and psychiatric symptoms in adulthood: national birth cohort study. BMJ 2001; 322: 1145.

13 Hotopf M, Carr S, Mayou R, Wadsworth M, Wessely S. Why do children have chronic abdominal pain, and what happens to them when they grow up? Population based cohort study. BMJ 1998; 316: 1196-200.

14 Batty GD, Morton SM, Campbell D, Clark H, Smith GD, Hall M, et al. The Aberdeen Children of the 1950s cohort study: background, methods and follow-up information on a new resource for the study of life course and intergenerational influences on health. Paediatr Perinat Epidemiol 2004; 18 221-39.

15 Leon DA, Lawlor DA, Clark H, Macintyre S. Cohort profile: the Aberdeen children of the 1950s study. Int J Epidemiol 2006; 35: 549-52.

16 Nishiwaki Y, Clark H, Morton SM, Leon DA. Early life factors, childhood cognition and postal questionnaire response rate in middle age: the Aberdeen Children of the 1950s study. BMC Med Res Methodol 2005; 5: 16.

17 Rutter M. Behavioural questionnaire to be completed by school teachers. Child Psychol Psychiatry 1967; 8: 1-11.

18 Power C, Stansfeld SA, Matthews S, Manor O, Hope S. Childhood and adulthood risk factors for socio-economic differentials in psychological distress: evidence from the 1958 British birth cohort. Soc Sci Med 2002; 55: 1989-2004.

19 Kresanov K, Tuominen J, Piha J, Almqvist F. Validity of child psychiatric screening methods. Eur Child Adolesc Psychiatry 1998; 7: 85-95.

20 North F, Syme SL, Feeney A, Head J, Shipley MJ, Marmot MG. Explaining socioeconomic differences in sickness absence: the Whitehall II Study. BMJ 1993; 306: 361-6

21 Upmark M, Lundberg I, Sadigh J, Allebeck P, Bigert C. Psychosocial characteristics in young men as predictors of early disability pension with a psychiatric diagnosis. Soc Psychiatry Psychiatr Epidemiol 1999; 34: 533-40.

22 Hotopf M, Wilson-Jones C, Mayou R, Wadsworth M, Wessely S. Childhood predictors of adult medically unexplained hospitalisations. Results from a national birth cohort study. Br J Psychiatry 2000; 176: 273-80. 